\title{
Audit on the role of Tranexamic Acid in Major Obstetric Haemorrhage - the unanswered questions that need addressing.
}

\author{
Robbins M, Hughes J, Sud A, Parbhoo P, Bhardwaj M \\ -Wexham Park Hospital, Dept of Anaesthetics, Slough, United Kingdom
}

\section{Background \& Previous Recommendations}

Postpartum haemorrhage (PPH) is the leading cause of maternal deaths worldwide and accounted for $16 \%$ of direct cause maternal deaths in the most recent UK MBRRACE report. 1,2

Tranexamic Acid (TXA) is a cheap, widely available anti-fibrinolytic on the WHO's List of Essential Medicines. It acts by reversibly binding to receptors on plasmin and plasminogen thereby preventing it's enzymatic breakdown of fibrin clots.

Before the release of the WOMAN trial there was no research looking at use of TXA in PPH. ${ }^{3}$ Guidelines were based on various studies in the surgical population and the more recent CRASH 2 trial, but there was inconsistency between the various organisations: WHO: "Tranexamic acid is recommended for the treatment of primary post-partum haemorrhage if uterotonics fail to control
the bleeding or if the bleeding is thought to be due to trauma." 1

AAGBI: “ Tranexamic Acid reduces total blood loss and should be given if postpartum haemorrhage is severe (>500ml after vaginal delivery and $>1000 \mathrm{ml}$ after caesarian delivery), at an initial dose of $1 \mathrm{~g} " 2$

RCOG: "Consideration should be given to the use of tranexamic acid in the management of PPH "

\section{Our Audit}

\section{Methods:}

Through case note review, anonymised data on management and documentation of $\mathrm{MOH}>2 \mathrm{~L}$ was collated in respect to when, why and how TXA was given.

\section{Results:}

TXA was given at $1 \mathrm{~g}$ dose in $43 \%$ of cases; these demonstrated partial correlation with total blood loss. Further $1 \mathrm{~g}$ was given in one case at $30 \mathrm{mins}$. and documentation

$83 \%$ of cases involved anaesthetic support. $68 \%$ of anaesthetic charts recorded total blood loss but none recorded incremental losses.

\begin{tabular}{|c|c|c|c|c|c|c|}
\hline Total & $\begin{array}{c}\text { Activation and } \\
\text { documentation } \\
\text { of } \mathrm{MOH} \\
\text { protocol }\end{array}$ & $\begin{array}{c}\text { Average } \\
\text { blood } \\
\text { loss } \\
\text { (median } \\
\mathbf{+} \text { IQR) }\end{array}$ & $\begin{array}{c}\text { TXA } \\
\text { given }\end{array}$ & $\begin{array}{c}\text { TXA } \\
\text { given } \\
<30 \\
\text { mins }\end{array}$ & $\begin{array}{c}\text { Requiring } \\
\text { blood } \\
\text { products }\end{array}$ \\
\hline $\begin{array}{l}\text { No. of } \\
\text { cases }\end{array}$ & 30 & 9 & $\begin{array}{c}2.2 \mathrm{~L} \\
(2.1- \\
3.0 \mathrm{~L})\end{array}$ & 13 & 10 & 10 \\
\hline
\end{tabular}

\section{Important points:}

1) TXA not regularly given.

2) 'Massive Obstetric Haemorrhage' protocol not always activated and/or documented.

3) Unrecorded continual and total blood loss shows failure in documentation of situational awareness.

1) WHO. WHO recommendations for the prevention and treatment of postpartum haemorrhage. Geneva: World Health Organisation, 2012.

2) Klein et al. AAGBI Blood transfusion Guielines 2016, John Wiley and sons on behalf of the Association of Anaesthetists of Great Britain and Ireland

3) Women Trial collaborators. Effect of early tranexamic acid administration on mortality, hysterectomy, and other morbidities in women with post-partum haemorrhage (WOMAN): an international, randomised, double-blind, placebocontrolled tria

\section{The Woman Trial}

- 20,060 women from 21 countries in a randomised, doubleblinded, placebo-controlled trial. Test group were administered $1 \mathrm{~g}$ TXA +/- further $1 \mathrm{~g}$ at 30 mins.

- Primary Outcome:

- Death due to bleeding.

- Secondary Outcomes:

- All cause mortality

- Thromboembolic events

- Surgical Interventions

- Complications

- Quality of life measurement

- The administration of TXA to women with PPH reduces deaths due to bleeding and laparotomy to control bleeding with no evidence of any adverse effects or complications.

- When given soon after delivery, TXA reduces death due to bleeding by nearly one third.

\section{In summary}

1) WHO recommendations require changing.

2) We recommend all obstetric and anaesthetic departments review their local policies in light of this new evidence.

3) Ensuring every clinicians knowledge and application of local guidelines and policies is essential; this includes proper documentation of ongoing losses and timely activation and documentation of haemorrhage protocols. The benefits of TXA in PPH will be lost unless effective application of other important practices are maintained. 